\title{
A Cholinergic Synaptically Triggered Event Participates in the Generation of Persistent Activity Necessary for Eye Fixation
}

\author{
Juan de Dios Navarro-López, ${ }^{1 \star}$ Juan Carlos Alvarado, ${ }^{2 \star}$ Javier Márquez-Ruiz, ${ }^{3}$ Miguel Escudero, ${ }^{3}$ \\ José M. Delgado-García, ${ }^{1}$ and Javier Yajeya ${ }^{4}$ \\ ${ }^{1}$ División de Neurociencias, Universidad Pablo de Olavide, 41013-Sevilla, Spain, ${ }^{2}$ Department of Neurobiology and Anatomy, Wake Forest University \\ School of Medicine, Winston-Salem, North Carolina 27157, ${ }^{3}$ Departamento de Fisiología y Zoología, Facultad de Biología, Universidad de Sevilla, 41012- \\ Sevilla, Spain, and ${ }^{4}$ Departamento de Fisiología y Farmacología, Facultad de Medicina, Instituto de Neurociencias de Castilla y León, Universidad de \\ Salamanca, 37007-Salamanca, Spain
}

An exciting topic regarding integrative properties of the nervous system is how transient motor commands or brief sensory stimuli are able to evoke persistent neuronal changes, mainly as a sustained, tonic action potential firing. A persisting firing seems to be necessary for postural maintenance after a previous movement. We have studied in vitro and in vivo the generation of the persistent neuronal activity responsible for eye fixation after spontaneous eye movements. Rat sagittal brainstem slices were used for the intracellular recording of prepositus hypoglossi $(\mathrm{PH})$ neurons and their synaptic activation from nearby paramedian pontine reticular formation (PPRF) neurons. Single electrical pulses applied to the PPRF showed a monosynaptic glutamatergic projection on PH neurons, acting on AMPA-kainate receptors. Train stimulation of the PPRF area evoked a sustained depolarization of PH neurons exceeding (by hundreds of milliseconds) stimulus duration. Both duration and amplitude of this sustained depolarization were linearly related to train frequency. The trainevoked sustained depolarization was the result of interaction between glutamatergic excitatory burst neurons and cholinergic mesopontine reticular fibers projecting onto $\mathrm{PH}$ neurons, because it was prevented by slice superfusion with cholinergic antagonists and mimicked by cholinergic agonists. As expected, microinjections of cholinergic antagonists in the PH nucleus of alert behaving cats evoked a gaze-holding deficit consisting of a re-centering drift of the eye after each saccade. These findings suggest that a slow, cholinergic, synaptically triggered event participates in the generation of persistent activity characteristic of PH neurons carrying eye position signals.

Key words: acetylcholine; glutamate; neuronal integrator; prepositus hypoglossi; saccades; oculomotor system

\section{Introduction}

In the oculomotor system, the presence of a neuronal integrator able to transform the eye velocity signal into a subsequent stable position signal has long been proposed (Robinson, 1981). The prepositus hypoglossi $(\mathrm{PH})$ nucleus, a neuronal structure involved in the maintenance of eye position after horizontal eye movements, has been suggested to play an important role in the integration of the horizontal gaze (Moschovakis, 1997; DelgadoGarcia, 2000). In support, it has been found that neurons in this nucleus project monosynaptically on extraocular motoneurons located in the abducens and oculomotor nuclei, as well as on many other structures involved in eye movement control (McCrea and Baker, 1985b). Extracellular recordings of $\mathrm{PH}$ neuronal

Received Jan. 21, 2004; revised April 18, 2004; accepted April 19, 2004.

This work was supported by Grants BI04-CT98-0546 (from the European Union) and PB98-0011, BFI2000-00936, BFI2000-1190, and BFI2002-01378 (from the Spanish Ministry of Science). We acknowledge the editorial help of R. Churchill and Dr. S. Ashenafi.

J.d.D.N.-L. and J.C.A. contributed equally to this work.

Correspondence should be addressed to Prof. José M. Delgado-García, División de Neurociencias, Universidad Pablo de Olavide, Ctra. de Utrera, Km. 1, 41013-Sevilla, Spain. E-mail:jmdelgar@dex.upo.es. DOI:10.1523/JNEUROSCI.0235-04.2004

Copyright $\odot 2004$ Society for Neuroscience $\quad 0270-6474 / 04 / 245109-10 \$ 15.00 / 0$ activity during spontaneous and vestibularly and visually evoked eye movements in monkeys and cats have shown the presence of cells encoding pure eye position (López-Barneo et al., 1982; Delgado-García et al., 1989) or related position velocity and velocity position signals (López-Barneo et al., 1982; DelgadoGarcía et al., 1989; McFarland and Fuchs, 1992). Moreover, permanent electrolytic lesions and transient pharmacological inactivations have shown that $\mathrm{PH}$ neurons are necessary for proper eye stability during positions of fixation (Cheron et al., 1986; Cheron and Godaux, 1987; Arnold et al., 1999; MorenoLópez et al., 1996, 2002).

The source of eye velocity signals arriving at $\mathrm{PH}$ neurons is excitatory burst neurons located in the paramedian pontine reticular formation (PPRF), rostral and ventral to the abducens motor nuclei (Igusa et al., 1980; Büttner-Ennever and Horn, 1997). Although several mechanisms have been proposed to explain neuronal integration in the $\mathrm{PH}$ nucleus (Keller and Kamath, 1975; Cannon et al., 1983; Goldman et al., 2003), the neuronal processes involved have not yet been elucidated. Interestingly, it has been shown recently that ipsilateral excitatory and contralateral inhibitory projections between eye positionrelated cells located in goldfish brainstem area I could mediate 
neuronal integration (Pastor et al., 1994; Aksay et al., 2001, 2003). The synaptic feedback among those neurons seems necessary for the temporal integration (Aksay et al., 2003), and the sustained firing rate observed in the integrator could be explained by changes in the amplitude or rate of the synaptic inputs to the area I position-related neurons, rather than by neuronal intrinsic membrane properties (Aksay et al., 2001). Considering that position-related neurons of the goldfish area I are equivalent to "principal" cells identified in the cat PH nucleus (McCrea and Baker, 1985a,b; Escudero et al., 1992), it could be suggested that a similar circuit for the temporal integration is present in the latter neuronal center (Aksay et al., 2003). Additional information is needed regarding synaptic mechanisms underlying the integration process. Here, it is proposed that the interaction between PPRF excitatory burst neurons and meso-pontine reticular cholinergic neurons (Higo et al., 1990; Semba et al., 1990; Barmack et al., 1992) is an important mechanism occurring at the synaptic level, which is necessary for the generation of the persistent neuronal activity recorded in $\mathrm{PH}$ neurons during eye fixations. Preliminary results have been published in abstract form (Navarro et al., 2003).

\section{Materials and Methods}

Preparation of slices. Experiments were performed in accordance with the European Union directive (609/86/EU) and current Spanish legislation (RD 233/89) for the use of laboratory animals in acute experiments. Female or male rats (23-33 d old; weight, 50-80 gm), raised in the animal colony of the University of Salamanca, were deeply anesthetized with halothane gas and decapitated. The skull and the first vertebral arch were removed, and the brain was excised and immersed in ice-cold (4$6^{\circ} \mathrm{C}$ ) oxygenated artificial CSF (ACSF), in which $\mathrm{NaCl}(117 \mathrm{~mm})$ was replaced with sucrose $(234 \mathrm{~mm}$ ) to maintain osmolarity. The brainstem was sectioned between the inferior colliculus and the obex, and sagittal slices (400 $\mu \mathrm{m}$ thick) were cut in cold oxygenated Ringer's solution using a vibratome (series 1000; Technical Products International, O'Fallon, $\mathrm{MO})$. Collected slices were placed in an incubation chamber and maintained there for $\sim 2 \mathrm{hr}$, at room temperature. For recordings, a single slice containing $\mathrm{PH}$ nucleus and rostral PPRF was transferred to an interface recording chamber (BSC-HT and BSC-BU; Harvard Apparatus, Holliston, MA) and perfused continuously with ACSF composed of (in mM) $117 \mathrm{NaCl}, 4.7 \mathrm{KCl}, 2.5 \mathrm{CaCl}_{2}, 1.2 \mathrm{MgCl}_{2}, 25 \mathrm{NaHCO}_{3}, 1.2 \mathrm{NaH}_{2} \mathrm{PO}_{4}$, and 11 glucose. The ACSF was bubbled with carbogen gas $\left(95 \% \mathrm{O}_{2} / 5 \% \mathrm{CO}_{2}\right)$ and maintained at $30 \pm 2{ }^{\circ} \mathrm{C}$. Additional details of this in vitro preparation were published previously (Yajeya et al., 2000).

In vitro recordings. Intracellular records from $\mathrm{PH}$ neurons were obtained with borosilicate glass microelectrodes (140-180 M $\Omega$; WPI, Sarasota, FL) filled with a potassium acetate solution $(3 \mathrm{M})$ and connected to the headstage of an intracellular recording amplifier (VF180; Biologic, Claix, France). Micropipette tips were always directed toward the rostral third of the PH nucleus. Neuronal recordings were characterized by studying their responses to depolarizing and hyperpolarizing current pulses. Only data from neurons that had stable resting potential with absolute values $>-55 \mathrm{mV}$ in the absence of DC holding currents, and presented overshooting action potentials, were collected for analysis. Spike amplitude and afterhyperpolarizing potentials were measured relative to threshold. Synaptic potentials were elicited orthodromically by stimulating the ipsilateral PPRF, using a monopolar stainless steel electrode ( $2 \mathrm{M} \Omega$ of effective resistance; WPI) and a programmable stimulator (MASTER-8; A.M.P.I., Jerusalem, Israel). Single, cathodal, squarewave pulses of $100-200 \mu \mathrm{sec}$ duration and $100-500 \mu \mathrm{A}$ intensity were adjusted to subthreshold values for orthodromic spike generation. Postsynaptic potentials were characterized according to their amplitude (as a function of the resting potential) and latency. When needed, the same stimulating pulses were also presented in trains of $100 \mathrm{msec}$, at $50-200 \mathrm{~Hz}$, or paired at variable interpulse intervals $(50-80 \mathrm{msec})$. Data were acquired and stored, as analog signal, on a videocassette using a modified video recorder (Physiorec-3; Cibertec, Madrid, Spain). Offline data acquisition and analysis were performed with the help of a CED 1401 interface (CED, Cambridge, UK) between the tape recorder and a personal computer, using the Mini Analysis Program, version 5.2.1 (Synaptosoft, Decatur, GA). Input resistance, spike amplitude and width, and synaptic potentials (rise and decay time and half width) were determined following procedures described previously (Yajeya et al., 2000).

Identification of stimulating and recording sites in the slices. At the end of electrophysiological recordings, selected neurons were stained by the intracellular injection of biocytin (McDonald, 1992) using an electrode filled with this substance in a potassium acetate solution (2 M). Positive current pulses of $0.2 \mathrm{nA}$, with a duty cycle $(6 \mathrm{~min})$ of $200 \mathrm{msec}$ on/200 msec off, were used. After injection, slices were transferred to an incubation chamber for $30 \mathrm{~min}$ and then fixed by immersion in $0.1 \mathrm{M}$ phosphate buffer (PB) with $1.25 \%$ glutaraldehyde for $35 \mathrm{~min}$. Fixed slices were embedded in a $2 \%$ solution of agar, cryoprotected with $30 \%$ sucrose in $\mathrm{PB}$, and sections $(45 \mu \mathrm{m})$ were cut using a freezing microtome (HM400R; Microm, Heidelberg, Germany). Sections were collected in $0.1 \mathrm{M}$ PB, rinsed three times in the same buffer, and then incubated with avidin-biotin-peroxidase complex (ABC; Vector Laboratories, Burlingame, $\mathrm{CA}$ ) for $3 \mathrm{hr}$ at room temperature. DAB was used as chromogen for visualization of the biocytin complex. The reaction was intensified with nickel ammonium sulfate. Every second section was counterstained with cresyl violet to determine the position of the filled neurons in the nucleus or the precise location of the stimulating electrode. Neurons were reconstructed from serial sections. Drawings were made using a camera lucida (Labophot; Nikon, Kawasaki, Japan) for all sections that contained a part of the reconstructed neuron. Drawings were superimposed by orienting the tracing paper to obtain the best fit between the corresponding sectioned elements.

Physiological experiments in vivo. Six adult cats $(2.4-3.7 \mathrm{~kg})$ of European strains, obtained from an authorized supplier (Iffa-Credo, Lyon, France), were used as experimental subjects. Experiments were performed in accordance with the European Union directive 609/86/EU for the use of laboratory animals in chronic experiments. Under general anesthesia (Nembutal; $35 \mathrm{mg} / \mathrm{kg}$, i.p.), cats were implanted bilaterally with Teflon-coated stainless steel coils sutured to the scleral margin of the eye. In the same surgical act, a $4 \times 4 \mathrm{~mm}$ hole was drilled through the occipital bone to allow access to the posterior brain stem via the cerebellum. Bipolar silver stimulating electrodes were implanted bilaterally on the VIth nerve, at its exit from the brain stem. A head-holding system, consisting of three bolts cemented to the skull perpendicular to the stereotaxic plane, was also implanted. Eye coils and stimulating electrodes were connected to a socket attached to the holding system. Recording experiments started 1 week after surgery. The animal was lightly restrained with an elastic bandage, and its head was fixed ( $21^{\circ}$ nose down) to the recording table by means of the head-holding system. A glass microelectrode was advanced through the cerebellum toward the abducens nucleus, which was identified by the recording of the antidromic field potential induced by electric stimulation of the ipsilateral VIth nerve. The PH nucleus was localized in the same sagittal plane and posterior to the abducens nucleus, as confirmed by recording the characteristic firing discharge of $\mathrm{PH}$ neurons during spontaneous and vestibularly induced eye movements (Escudero et al., 1992). Injections were performed by means of glass micropipettes with tip diameters of 7-8 $\mu \mathrm{m}$, filled with the corresponding drug dissolved in $0.1 \mathrm{M} \mathrm{PB}, \mathrm{pH}$ 7.4. Air pulses $\left(1 \mathrm{~kg} / \mathrm{cm}^{2} ; 1 \mathrm{sec}\right)$ were applied with an air pressure device connected to the injection micropipette to deliver $40 \mathrm{nl} /$ pulse. All injections were restricted to the rostral third of the $\mathrm{PH}$ nucleus. A total of four or more effective injections of each of the four selected drugs were performed. A minimum of $3 \mathrm{~d}$ was allowed between successive injections in the same animal. Eye movements were recorded with the scleral search coil technique. Spontaneous eye movements were recorded continuously in complete darkness and in light, with the micropipette in place, before and after injections. After each drug injection, eye movements were recorded in alternated light and dark periods ( 2 min each) up to a maximum of $90 \mathrm{~min}$. Eye movements were calibrated at the beginning of each experimental session by rotating $\left( \pm 10^{\circ}\right)$ the magnetic field frame about both the horizontal and vertical planes. Eye movements were stored on an eight-channel videotape recording system and fed into a computer for 
A

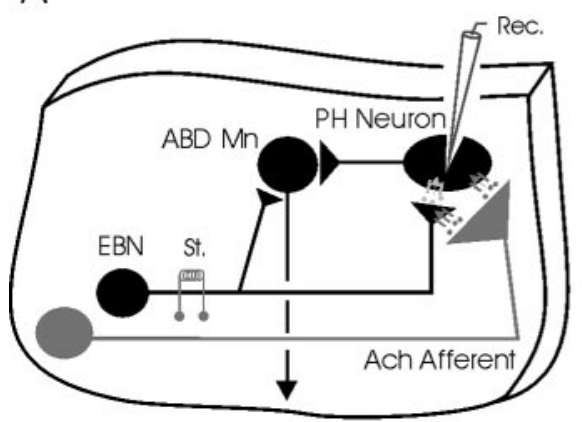

B

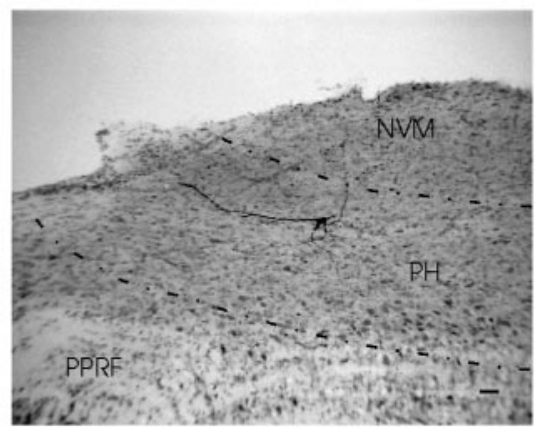

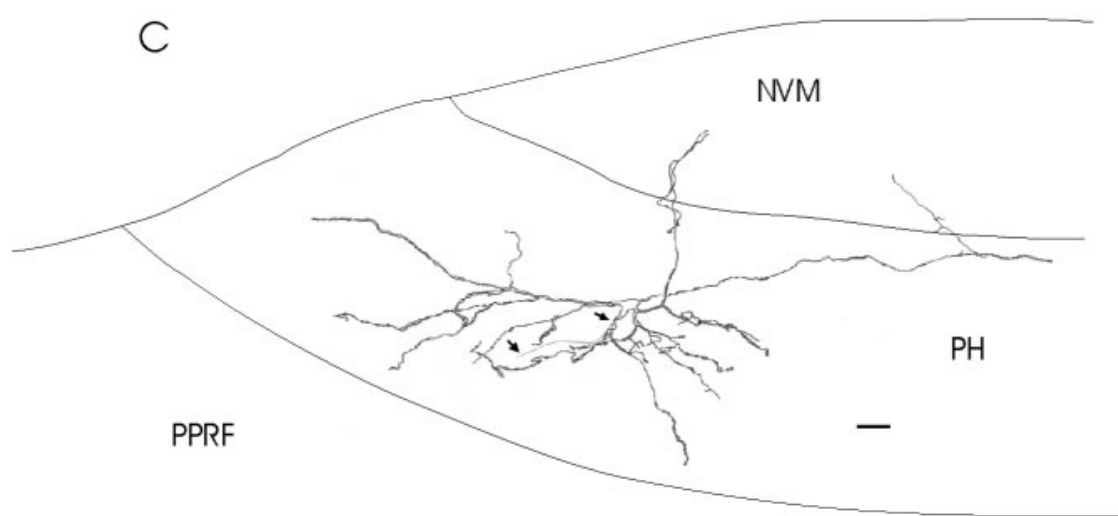

Figure 1. Diagrams of stimulation and recording sites. $A$, A diagram illustrating the circuits present in the sagittal brainstem slice used in this study. Excitatory burst neurons (EBN) are located in the PPRF and project monosynaptically on abducens motoneurons (ABD Mn) and on PH neurons. Stimuli applied to the PPRF also activate descending cholinergic axons from pontomesencephalic areas. See Results for details and references. $B, A$ photomicrograph of a PH neuron stained after intracellular recording. $C$, A drawing showing the reconstruction of the neuron illustrated in $B$. This neuron type corresponds to a principal cell (McCrea and Baker, 1985a). The two small arrows indicate initial trajectory of the axon. Scale bars: B, C, $50 \mu \mathrm{m}$. NVM, Medial vestibular nucleus.

offline analysis. Additional details of this chronic preparation were published previously (Escudero et al., 1992; Moreno-López et al., 1996, 2002).

Analysis of data collected from in vivo experiments. During spontaneous eye movements, the alterations induced by drug injections in the $\mathrm{PH}$ nucleus consisted of a nystagmus with curved or straight slow phases separated by quick resetting movements and/or drifts toward a central position after eccentric saccades. Nystagmic slow phases with a duration $>0.5 \mathrm{sec}$ were fitted separately, by the least squares method, to a linear or single exponential equation and were considered to be linear, or exponential, when $>80 \%$ of the analyzed phases had a correlation coefficient $>0.99$ or $>0.90$, respectively. For linear adjustment, the slope of the line was measured before and after each drug injection (see Fig. $9 A$, inset). In light, the postsaccadic centripetal drifts evoked by drug injections did not correlate significantly to a single exponential equation. Thus, to characterize the temporal evolution of drug effects on the maintenance of gaze, the postsaccadic centripetal drift was calculated as the area (in degrees by seconds) between the actual eye position drift and the theoretical "maintained" eye position for the $0.6 \mathrm{sec}$ after each saccade (see Fig. 9 C, inset). Because these area values depended on the velocity of the preceding saccade and on the eye position at the end of this saccade, a linear multiple regression test was performed to determine the coefficients for each injection. These coefficients were used to correct the area values by subtracting position and velocity effects. The corrected area, named here "missed eye position value" in degrees by seconds, was then expressed as the percentage of the maximum effect for each injection.

Drugs. All chemicals used in this study were applied by superfusion in the ACSF and introduced into the recording chamber by means of a perfusion pump (2115 Multiperspex pump; LKB-Bromma, Bromma, Sweden). The chemicals used were atropine sulfate, CNQX, APV, McN-A-343, and TTX from Sigma (St. Louis, MO); pirenzepine (Tocris; Biogen Científica, S.L., Madrid, Spain); and methylyl-caconitine and carbachol (Research Biochemicals, Natick, MA). Atropine sulfate, McN-A-343, pirenzepine, and carbachol were selected for the in vivo study.

Statistics. Unless indicated otherwise, the electrophysiological data are always expressed as mean \pm SEM. In all cases, $n$ represents the number of averaged neurons. Unless indicated otherwise, action and synaptic potentials were averaged (five or more) before quantitative analysis. Statistical analysis of collected data was performed using a paired Student's $t$ test and, when necessary, by one-way ANOVA. Statistical significance was determined at a level of $p \leq 0.05$.

\section{Results}

Membrane properties of $\mathrm{PH}$ neurons

Sagittal slices used in this study allowed an easy identification of the anatomical limits of the PH nucleus (Fig. 1). Intracellular recordings $(n=125)$ were made from neurons located in the rostral third of the nucleus, because this is the place where principal cells projecting to the abducens nucleus and other oculomotor structures are located (McCrea and Baker, 1985a; Escudero et al., 1992). Recorded neurons did not present action potentials spontaneously at resting potential values $(-66.6 \pm$ $2.5 \mathrm{mV})$. The direct activation of these neurons by depolarizing current injections (0.1-0.6 nA) generated action potentials or a train of spikes with a slow adaptation in all of the cases. The mean input resistance of the neurons was $10.55 \pm 0.6 \mathrm{M} \Omega$, the mean membrane time constant was $29.9 \pm$ $3.3 \mathrm{msec}$, and the threshold potential was $51.1 \pm 1.0 \mathrm{mV}$. The spike amplitude was $76.6 \pm 1.4 \mathrm{mV}$, with a duration of $1.28 \pm$ $0.06 \mathrm{msec}$, a rise time of $0.28 \pm 0.01 \mathrm{msec}$, a decay time of $0.32 \pm$ $0.02 \mathrm{msec}$, and a half width of $0.62 \pm 0.03 \mathrm{msec}$ (Fig. $2 \mathrm{~A}$ ).

After DC injection (Fig. 2A) or electrical stimulation of the PPRF (Fig. 2B), PH neurons included in this study presented a biphasic afterhyperpolarization (AHP), consisting of a fast hyperpolarization (fAHP), continuing the repolarizing phase of the action potential, with an amplitude of $9.2 \pm 1.0 \mathrm{mV}$, followed by a medium AHP (mAHP) with an amplitude of $13.2 \pm 0.7 \mathrm{mV}$ and a duration of $78.29 \pm 4.19 \mathrm{msec}$ (Fig. $2 A$ ). The peak of the fAHP was always negative $(8.2 \pm 1.3 \mathrm{mV})$ with respect to resting potential values. The fAHP increased in amplitude with membrane hyperpolarization and decreased with membrane depolarization $(r=0.71 ; p<0.05)$. The two phases were separated by an afterdepolarization (ADP), which was generated $2.14 \pm 0.21 \mathrm{msec}$ after the spike. The ADP amplitude was voltage dependent, increasing with membrane hyperpolarization and decreasing with membrane depolarization $(r=0.68 ; p<0.01)$.

Fifteen of the 125 recorded neurons were successfully filled. Morphological reconstruction of biocytin-injected neurons showed that they were fusiform or piriform in shape $(25.3 \pm 1.6$ $\mu \mathrm{m}$ mean diameter), with three to six primary dendritic trunks 
leaving the soma in opposite directions (Fig. $1 B, C$ ). Primary dendrites divided into two or three secondary dendrites at 25-30 $\mu \mathrm{m}$ from the soma and extended radially around it, frequently reaching the paragigantocellular formation and parts of the medial vestibular nuclei included in the slice. For five neurons, the axon could be followed crossing the $\mathrm{PH}$ and entering the adjacent medial longitudinal fascicle. The morphology of these neurons is consistent with that of the principal cells identified in the $\mathrm{PH}$ nucleus of cats by HRP injections and projecting to many brainstem-located oculomotor sites, including the abducens nucleus (McCrea and Baker, 1985a).

Other neurons recorded in the anatomical limits of the $\mathrm{PH}$ nucleus $(n=27)$ did not present a biphasic AHP and did present ventrally directed axonal trajectories $(n=6)$ not reaching the medial longitudinal fascicle. Such neurons were considered to be "medusa cells" (McCrea and Baker, 1985a), projecting probably to cerebellar structures, and were not included in this study.

\section{Response of PH neurons to ipsilateral PPRF stimulation}

To characterize the synaptic nature of oculomotor signals afferent to $\mathrm{PH}$ neurons from the PPRF, this region was electrically stimulated at subthreshold values (Fig. $2 B$ ). The synaptic responses evoked on PH neurons were EPSPs in all cases $(n=35)$. The evoked EPSPs had a mean latency of $2.60 \pm 0.32 \mathrm{msec}$, a duration of $68.8 \pm 20.6 \mathrm{msec}$, a rise time of $8.07 \pm 3.26 \mathrm{msec}$, a decay time of $20.5 \pm 9.8 \mathrm{msec}$, and a half width of $21.2 \pm 9.2$ msec. The EPSP amplitude showed a graded nature, depending on stimulus intensity (Fig. $2 B$ ) and on resting membrane potential (data not shown), without any evident change in latency (with train stimuli up to $200 \mathrm{~Hz}$ ), suggesting its monosynaptic nature.

Moreover, as shown in Figure 2, $C$ and $D$, train stimulation (50-200 Hz, $100 \mathrm{msec}$ ) of the PPRF evoked a sustained depolarization of $\mathrm{PH}$ neurons exceeding the end of the train by hundreds of milliseconds. This depolarization was able to evoke a train of action potentials that reached peak frequencies $\leq 150$ spikes $/ \mathrm{sec}$. The amplitude and duration of this depolarization were linearly related ( $r \geq 0.95 ; p \leq 0.001)$ to stimulus frequency during the train, with slopes of $0.023 \mathrm{mV} / \mathrm{Hz}$ and $1.44 \mathrm{msec} / \mathrm{Hz}$, respectively (Fig. 2E,F).

\section{Effects of DC stimulation on the firing properties of $\mathrm{PH}$ neurons}

An attempt was made to evoke the same sustained depolarization of PH neurons by DC injection to check whether it was dependent on the intrinsic active properties of the membrane of $\mathrm{PH}$ cells. The depolarization of PH neurons $(n=25)$ by means of an injection of DC (0.1-0.6 nA) evoked spontaneous discharges ranging from 5 to 40 spikes/sec (Fig. $3 A, B$ ). This firing activity stopped immediately after the end of current-evoked depolarization, with no sign of any over-running depolarization.

Superfusion with TTX ( $1 \mu \mathrm{M} ; n=7)$ blocked the action potentials elicited in $\mathrm{PH}$ neurons by depolarizing pulses (Fig. $3 C$ ).

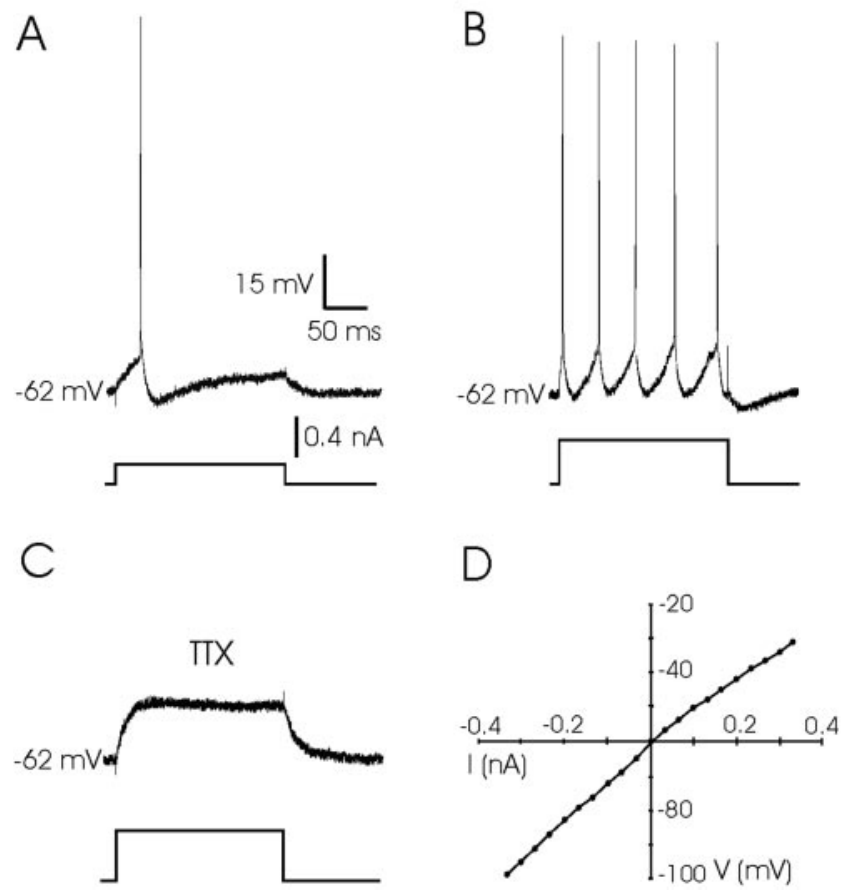

Figure 3. Response of $\mathrm{PH}$ neurons to $\mathrm{DC}$ injection. $A, A$ single action potential evoked in a $\mathrm{PH}$ neuron with a depolarizing current pulse $(0.2 \mathrm{nA}, 200 \mathrm{msec}) . B, A$ train of action potentials evoked in the same neuron when the current pulse was increased to $0.5 \mathrm{nA}$. Note the absence of any plateau potential after neuron depolarization by $D C$ injection. C, Example of the response of the same PH neuron after superfusion with $\operatorname{TTX}(1 \mu \mathrm{M})$ in the presence of a depolarizing pulse of $0.4 \mathrm{nA}$. D, Current-voltage ( $I-\eta$ relationships for a $\mathrm{PH}$ neuron in which voltage-dependent sodium currents were blocked with TTX $(1 \mu \mathrm{M})$. The resting membrane potential for the neuron was $-60 \mathrm{mV}$. Current pulses were always $200 \mathrm{msec}$ in duration.

These results indicated a $\mathrm{Na}^{+}$dependence of action potentials in $\mathrm{PH}$ neurons. Moreover, the $I-V$ relationships for $\mathrm{PH}$ neurons $(n=7)$, when voltage-dependent $\mathrm{Na}^{+}$channels were blocked with TTX, were linear $(r \leq 0.75 ; p<0.001)$ (i.e., without any 
A

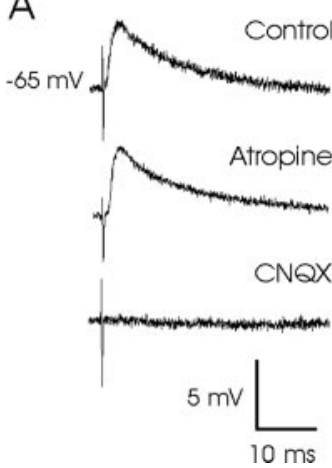

B
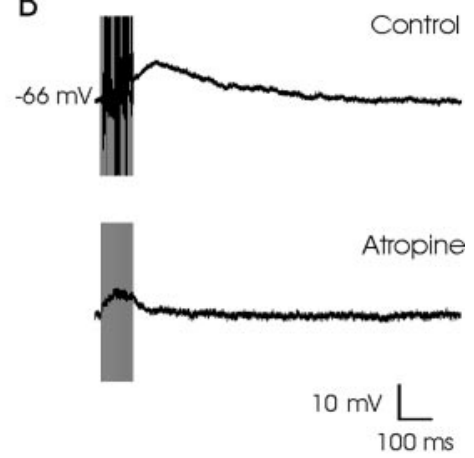

Figure 4. Glutamatergic nature of PPRF synapses on PH neurons and the depolarizing effect of cholinergic inputs on the same postsynaptic neuron. A, Top, EPSP evoked in a PH neuron by a single subthreshold stimulus applied to the PPRF. Note that the synaptic potential was not affected by atropine $(1.5 \mu \mathrm{M})$ but that superfusion with CNQX $(10 \mu \mathrm{M})$ completely removed the evoked EPSP. B, Train $(200 \mathrm{~Hz})$ stimulation of the same PPRF site evoked a large and sustained post-train depolarization of the same $\mathrm{PH}$ neuron. This sustained depolarization was impossible to evoke in the presence of atropine sulfate $(1.5 \mu \mathrm{M})$.

A

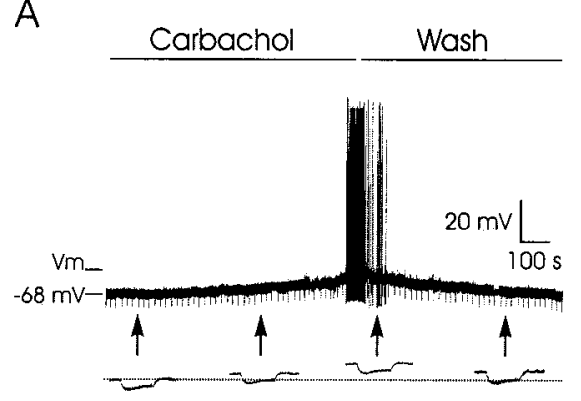

B
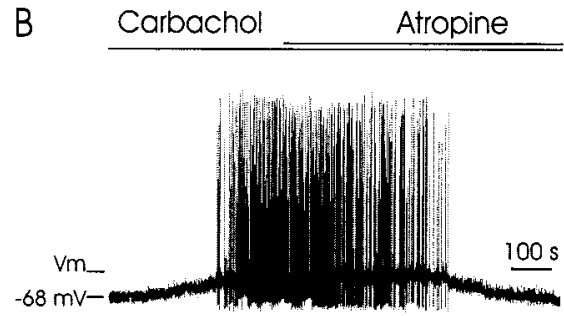

C

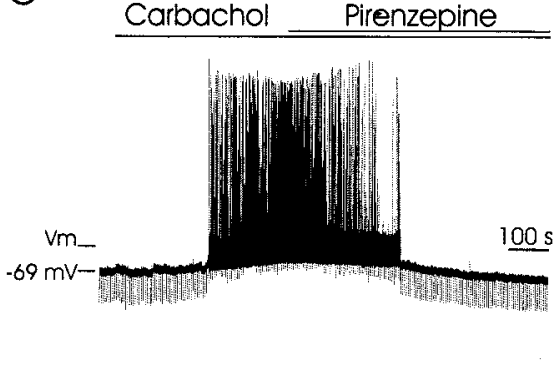

$D$

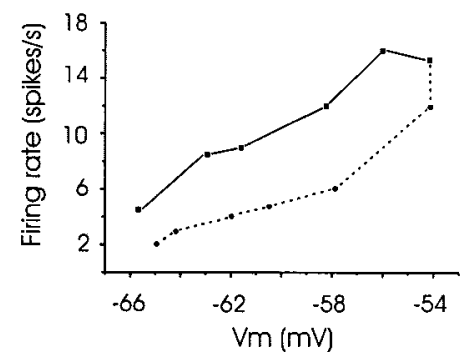

Figure 5. Depolarizing effects of carbachol on PH neurons. A, Intracellular recording of a PH neuron in the presence of carbachol $(25 \mu \mathrm{M})$. Note a slow depolarization of the recorded cell with a nonsignificant decrease in membrane input resistance. At threshold, the neuron started the generation of action potentials. The depolarizing effect of carbachol disappeared after the cell was washed with the bathing solution. The arrows indicate the points at which recordings were expanded in time to show membrane potential during the presentation of hyperpolarizing pulses $(0.3 \mathrm{nA}, 300 \mathrm{msec})$. The dotted line indicates the membrane resting potential. The maximum depolarizing level evoked by carbachol is indicated (Vmax). B, C, The depolarizing effects of carbachol were blocked by atropine $(1.5 \mu \mathrm{M})$ and by pirenzepine $(0.5 \mu \mathrm{m})$. Maximum depolarizing levels evoked by carbachol in $B$ and $($ are indicated (Vmax). In C, hyperpolarizing current pulses $(0.3 \mathrm{nA}, 300 \mathrm{msec}$ ) were presented at a frequency of $0.2 \mathrm{~Hz}$. D, A plot of membrane potential ( $\mathrm{Vm}$, in millivolts) against neuron firing rate (spikes/second) for data shown in C. The continuous line indicates firing frequencies reached when membrane potential was changing in the depolarizing direction. The dotted line indicates neuron firing when the membrane potential was going in the hyperpolarizing direction. Vmax, Maximum membrane potential evoked by carbachol superfusion. Calibration is the same for $A-C$.

noticeable rectification in the physiological voltage values) (Fig. $3 D)$. Accordingly, there was no sign in the postsynaptic membrane properties that could explain the sustained depolarization evoked by $100 \mathrm{msec}$ trains of electrical stimuli applied to the PPRF. In consequence, this depolarization has a synaptic origin and is not related to intrinsic membrane properties.

\section{Glutamatergic nature of PPRF synaptic terminals on} $\mathrm{PH}$ neurons

As shown in Figure $4 A$, the EPSPs evoked by subthreshold electrical pulses applied to the ipsilateral PPRF were completely tatory synaptic response in PH nourons evoked by the sube old stimulation of the ipsilateral PPRF was essentially mediated by glutamate-activating AMPA-kainate receptors. Indeed, superfusion with APV (a specific blocker of NMDA receptors; $50 \mu \mathrm{M}$; $n=10$ ), without the addition of CNQX, had no effect on EPSPs evoked by the electrical stimulation of the PPRF region, indicating that NMDA receptors were not present in this synapse. Furthermore, superfusion with atropine sulfate (a nonspecific antagonist of cholinergic receptors; $1.5-4.5 \mu \mathrm{M}$ ) had no noticeable effect on EPSPs evoked in PH neurons by single, subthreshold

Postsynaptic and presynaptic effects of cholinergic drugs on the firing properties of $\mathrm{PH}$ neurons

It is known that train stimuli $(>30 \mathrm{~Hz})$ are able to activate cholinergic axons (Moises et al., 1995; Faber and Sah, 2002), and it has been described that cholinergic axons from pontomesencephalic reticular formation nuclei reach the PH nucleus (Carpenter et al., 1987; Higo et al., 1990; Semba et al., 1990). In this regard, we assumed that those cholinergic neurons and/or axons were also activated by the electrical stimulation of the PPRF and that the sustained depolarization evoked in PH neurons could have a cholinergic origin. Indeed, the superfusion with atropine sulfate $(1.5 \mu \mathrm{M} ; n=7)$ was able to remove the sustained depolarization evoked by a train applied to the PPRF area (Fig. 4B).

Superfusion of the slice with the cholinergic agonist carbachol $(25 \mu \mathrm{M})$ was able to evoke a slow-building and longlasting depolarization (peak at $\geq 12.3 \mathrm{mV}$; $n=25$ ) of intracellularly recorded $\mathrm{PH}$ neurons. This depolarization even reached threshold values $(80 \%$ of the cases; $n=25$ ) to evoke action potentials (Fig. 5). The slope of PH neuron depolarization evoked by carbachol superfusion presented values ranging from 0.05 to 0.2 $\mathrm{mV} / \mathrm{sec}(n=15)$. This depolarization took place without any noticeable change in the input resistance of the recorded neuron, as calculated indirectly with the application of hyperpolarizing pulses (Fig. $5 A$ ).

The firing frequency evoked by the carbachol-induced depolarization was lower than that generated by DC-evoked depolarization at values close to threshold (peak values of $18.7 \pm 2.6$ against $41.9 \pm 5.6$ spikes/sec, respectively), indicating that carbachol-evoked peak firing of $\mathrm{PH}$ neurons represented only some $45 \%$ of that evoked by DC depolarization of the same neurons $(n=8)$. Moreover, action potentials evoked during carbachol-induced depolarization were $30 \%$ smaller $(t=3.63 ; p<0.01)$ than those generated by DC injection (ranges: $30-70$ against $60-80 \mathrm{mV}$, respectively) (Figs. 3, 5). 
The mAHP duration of the action potential was significantly $(t=5.04 ; p<0.001)$ longer in $\mathrm{PH}$ neurons depolarized with carbachol $(120.11 \pm 11.40 \mathrm{msec})$ than in those depolarized by DC injection $(72.83 \pm 6.39 \mathrm{msec})$. This change represented an increment of $65 \%$ in the duration of the mAHP, which could partly explain the differences in peak firing frequencies evoked by carbachol and DC injection indicated above (data not shown).

The depolarizing effects of carbachol were abolished by superfusion with atropine sulfate $(1.5-4.5 \mu \mathrm{M} ; n=14)$, indicating that the response was mediated by muscarinic receptors (Fig. $5 B$ ). To further characterize the subtype of muscarinic receptor involved in the carbachol-evoked depolarization, pirenzepine (a selective blocker of muscarinic M1 receptors) (Yajeya et al., 2000) was added to the perfusion solution $(0.5 \mu \mathrm{M})$. In all cases $(n=7)$, the carbachol-evoked depolarization was abolished, indicating the involvement of $\mathrm{M} 1$ receptors in carbachol actions on the membrane of PH neurons (Fig. 5C). Interestingly, the level of depolarization evoked by carbachol was linearly related (slope, 1.094 spikes/mV; $r=0.92 ; p>0.001$ ) with neuronal firing rate (Fig. $5 D)$. This relationship seems to be necessary in vivo for evoking a proportional firing rate for each position of the eye in the orbit. When the effects of carbachol were blocked by superfusion with pirenzepine (Fig. $5 C$ ), the linear relationship was maintained, but with a smaller slope ( 0.823 spikes $/ \mathrm{mV} ; r=0.95 ; p>0.001)$. The noticeable hysteresis described here (i.e., different firing rates for the same resting potential, depending on the depolarizing or repolarizing direction of membrane potential values) has also been described in both abducens motoneurons and $\mathrm{PH}$ neurons in vivo and is of physiological significance because of the opposite phenomena (extraocular muscles presenting greater strength for the same length when relaxing than when contracting) (DelgadoGarcía et al., 1989).

To confirm the postsynaptic nature of the depolarizing effects of carbachol on $\mathrm{PH}$ neurons, all possible action potentials spontaneously present were removed by TTX superfusion $(1 \mu \mathrm{M} ; n=$ 8) of the slice (Fig. 6). The effective blockage of all action potentials was checked by repetitive stimulation (at $0.2 \mathrm{~Hz}$ ) of the PPRF. Figure $6 B$ shows the progressive disappearance of EPSPs evoked in a PH neuron after TTX superfusion. During TTX superfusion, the recorded cell did not evoke any action potential, even after DC injections (Fig. 6B, asterisk). In this situation, the superfusion with carbachol $(25 \mu \mathrm{M} ; n=8)$ evoked a depolarization not accompanied by the generation of any action potential.

The possibility of some additional presynaptic effects of cholinergic drugs on PPRF axon terminals on PH neurons was also checked, using the paired-pulse paradigm (Mennerick and Zorumsky, 1995; Huang et al., 1996; Yajeya et al., 2000). It has been reported (Huang et al., 1996; Thompson, 2000; Fernández de Sevilla et al., 2002) that any change in the response evoked by the second stimulus (S2) in relation to the first (S1) will be indicative of a presynaptic action $(100 \times \mathrm{S} 2 / \mathrm{S} 1)$. Explored PH neurons $(n=$ $10)$ presented a reduction $(61.00 \pm 0.03 \%)$ in EPSP amplitude evoked by the second stimulus (S2) presented to the PPRF in relation to the first (S1), at an interval of $50-100 \mathrm{msec}$ (Fig. 7A, row 1). As shown in Figure 7A (row 3), carbachol superfusion (25 $\mu \mathrm{M}$ ) was able both to decrease the amplitude of the EPSP evoked by the electrical stimulation of the PPRF by the $S 1$ stimulus and to increase the S2/S1 ratio with respect to control values $(88.90 \pm$ 0.05 against $61.00 \pm 0.03 \%$; $p<0.01$ ). This effect could be considered presynaptic, because the depolarizing effect of carbachol on the postsynaptic $\mathrm{PH}$ neuron was canceled out by currentholding of the postsynaptic cell, at resting membrane potential values. Superfusion with caconitine $(0.1 \mu \mathrm{M})$, a potent antagonist
A
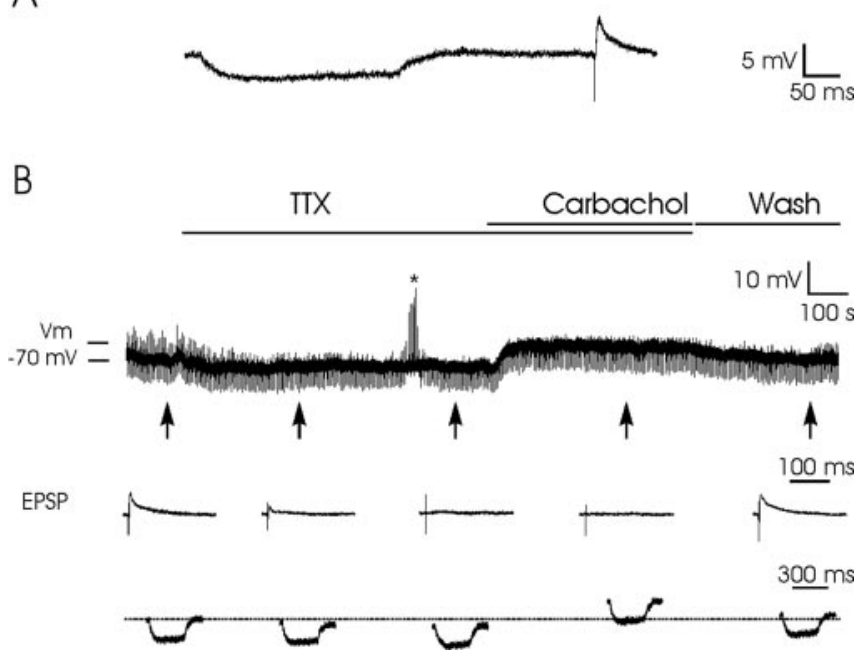

Figure 6. Postsynaptic depolarizing effects of carbachol on PH neurons. $A$, An example of the experimental protocol. A hyperpolarizing current pulse $(0.3 \mathrm{nA}, 300 \mathrm{msec}$; at a frequency of 0.2 $\mathrm{Hz}$ ) was presented $300 \mathrm{msec}$ in advance of a subthreshold stimulus applied to the PPRF to evoke an EPSP in the postsynaptic PH neuron. $B$, The addition of TTX $(1 \mu \mathrm{M})$ to the bath removed EPSPs because of action potential blocking. The asterisk indicates that the cell was not responsive to intracellular current injection. In this situation, superfusion with carbachol (25 $\mu \mathrm{M})$ evoked a noticeable depolarization of the membrane potential, with no evident change in the input resistance of the recorded neuron. The maximum depolarizing level evoked by carbachol is indicated $(\mathrm{Vm})$. The depolarizing effect of carbachol disappeared after the cell was washed with the bathing solution. Washing also allowed the reappearance of EPSPs evoked by PPRF stimulation. The arrows indicate the points at which recordings were expanded in time to show EPSPS evoked by PPRF stimulation and membrane potential during the presentation of hyperpolarizing pulses. The dotted line indicates the membrane resting potential. Vm, Maximum membrane potential evoked by carbachol superfusion.

of nicotinic receptors (Marchi et al., 2002), did not modify the presynaptic depressant effects of carbachol (Fig. 7). In contrast, atropine sulfate $(1.5 \mu \mathrm{M})$ completely abolished the effects of carbachol, suggesting the presence of muscarinic receptors in the presynaptic terminals of PPRF neurons projecting monosynaptically on PH neurons. Thus, the ACh has a double effect: a sustained depolarization of postsynaptic PH neurons after PPRF activation and a presynaptic action, on PPRF axon terminals, decreasing glutamate release. The latter effect could help in a sharp termination of PPRF eye velocity signals on PH neurons (Delgado-García et al., 1989)

\section{Effects of cholinergic drugs on spontaneous eye movements in alert cats}

To characterize the effects of selected drugs on eye movements in alert behaving animals, agonists (carbachol and McN-A-343) and antagonists (atropine and pirenzepine) of cholinergic receptors were unilaterally injected in the rostral PH nucleus (Fig. 8). Unilateral injections of carbachol (40-120 nl; $125 \mu \mathrm{M})$ and $\mathrm{McN}$ A-343 (40-120 nl; $250 \mu \mathrm{M})$ induced a nystagmus with linear slow phases directed contralaterally to the injected side. In both cases, the nystagmus was very much evident in darkness, whereas in light the nystagmus was reduced or absent. In all cases $(p<0.05)$, nystagmus induced by carbachol was slower in reaching maximum values than that induced by McN-A-343 (Fig. 9A, B; Table 1). Unilateral injections of atropine ( $40-120 \mathrm{nl} ; 100 \mathrm{~mm})$ induced centripetal postsaccadic drifts in the light, with a time constant of $0.196 \pm 0.018 \mathrm{sec}(n=4$; measured at peak response of the injected drug). In darkness, the atropine injection always induced a nystagmus with slow phases curved and directed ipsilaterally to 
A
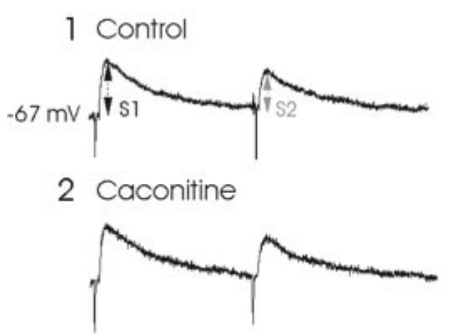

3 Caconitine + Carbachol

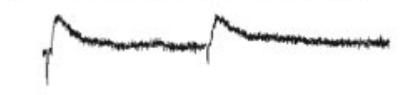

4 Caconitine + Carbachol + Atropine

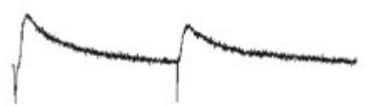

B
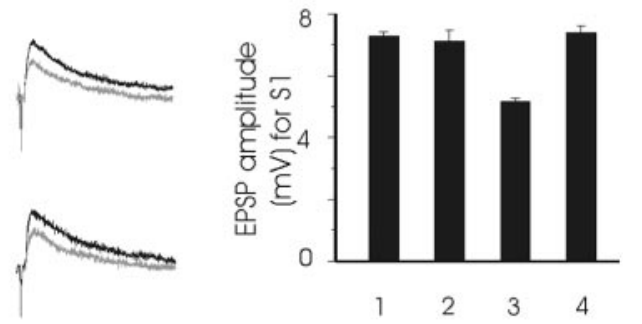

D

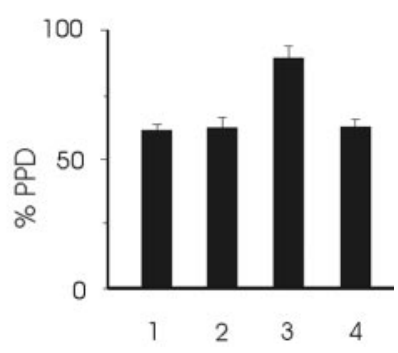

Figure 7. EPSPs evoked in PH neurons by paired pulses presented to the PPRF and their presynaptic modulation by carbachol and other cholinergic drugs. A, Sample of EPSP records evoked by paired stimuli (S1-S2; interval, $70 \mathrm{msec}$ ) presented to the ipsilateral PPRF in the control condition (row 1) and during caconitine (row 2; $0.1 \mu \mathrm{M}$ ), caconitine plus carbachol (row 3; $25 \mu \mathrm{M}$ ), and caconitine plus carbachol plus atropine (row 4; $1.5 \mu \mathrm{m}$ ). Note that carbachol depressed S1- and S2-evoked EPSPs and that the effect was reversed by atropine. Membrane potential of the postsynaptic $\mathrm{PH}$ neuron was maintained at its resting level by current injection to cancel out the postsynaptic depolarization evoked by carbachol. $B$, Superimposition of EPSPs obtained by S1 (black recordings) and S2 (gray recordings) stimuli shown in $A$. C, Histograms with mean values for EPSP amplitude (in millivolts; $n=10$ ) obtained for S1 presentations. D, Paired-pulse depression (PPD) test. Histograms with mean values (in millivolts; $n=10$ ) obtained for the equation \%PPD $=$ S2/S1 $\times 100$, indicating a significant recovery, evoked by carbachol, of the depression induced by the second stimulus ( $\mathrm{S} 2)$. These results suggested a presynaptic action of carbachol.

the injected side (Fig. 8). Injections of pirenzepine (40-120 nl; 0.1-1 $\mu \mathrm{M}$ ) were more elusive and produced effects only occasionally (4 from 12; i.e., 33\% of the injections). Nevertheless, the effects induced by pirenzepine were always identical: a centripetal postsaccadic drift in the light (time constant of $0.211 \pm 0.023 \mathrm{sec}$; $n=4)$. In darkness, pirenzepine evoked nystagmus occasionally, and sometimes, even as a consequence of the same injection, slow phases that reversed spontaneously were recorded. In all cases, the slow phases of the pirenzepine-induced nystagmus were curved. The time course to reach the maximum effect was faster for pirenzepine than for atropine $(p<0.05)$ (Fig. 9C,D; Table 1). Carbachol and atropine presented similar $T_{\mathrm{m}}$ (time to evoked peak response) values (Fig. $9 A, B$; Table 1 ), and $>1.9$ times larger $(p<0.05)$ than those obtained for McN-A-343 and pirenzepine (Fig. 9C,D; Table 1). These results are probably related to the specificity of each drug to M1 receptors. No significant differences were found in the $T_{50}$ value for any of the drugs used for in vivo experiments (Table 1 ).

\section{Discussion}

Role of PH neurons in the generation of eye position signals

To maintain the position of the eye after a saccade, extraocular motoneurons need a persistent activity called "eye position signal” (Cannon and Robinson, 1987; Delgado-García et al., 1989; Fukushima et al., 1992; Moschovakis et al., 1996; Moschovakis, 1997). Because PPRF excitatory burst neurons fire only slightly in advance and during part of the ongoing saccade, a repeated question has been how do neuronal circuits implicated in eye movements generate eye position signals. For the horizontal oculomotor system, neurons carrying pure (or closely related) eye position signals have been recorded in the $\mathrm{PH}$ nucleus of cats and monkeys
(López-Barneo et al., 1982; DelgadoGarcía et al., 1989; McFarland and Fuchs, 1992; Moschovakis et al., 1996) and in the brainstem area I of goldfish (Pastor et al., 1994; Aksay et al., 2001, 2003). In goldfish, intracellular injection of current in area I neurons failed to generate persistent activity; however, when the current was applied extracellularly near the integrator area, an ipsilateral direct drift of the eyes occurred (Aksay et al., 2001). These findings suggest that synaptic mechanisms, rather than membrane properties of integrator neurons, are implicated in the generation of persistent activity. Consistent with this latter possibility, DC injection in $\mathrm{PH}$ neurons did not evoke sustained potentials. However, train stimulation of the PPRF area produced a sustained depolarization of $\mathrm{PH}$ neurons that exceeded the duration of the stimulus and was linearly related, in amplitude and duration, with train frequency. As shown here, synaptic effects of the PPRF on PH cells are mediated by glutamate, acting on AMPA-kainate receptors. This finding is relevant, considering that the NMDA/AMPA receptor ratio plays an important role in persistent activity (Aksay et al., 2003).

The fact that the duration found here of the sustained depolarization after the stimulation of the PPRF was not large enough to explain by itself the integration could be attributed to the in vitro preparation. In vivo, motor commands for horizontal eye saccades are generated in the PPRF (Igusa et al., 1980; Escudero and Delgado-García, 1988; Fukushima et al., 1992; Moschovakis et al., 1996; Büttner-Ennever and Horn, 1997) by short-lead excitatory burst neurons that project monosynaptically on abducens and PH neurons, encoding saccade duration, amplitude, and velocity. In slices, there is a lack of substrate for positive feedback from other brainstem nuclei related to eye movements, a fact-producing disfacilitation of $\mathrm{PH}$ neurons (Aksay et al., 2003). Under these conditions, the reported depolarization (a few hundred milliseconds) could be considered too short for eye fixations in vivo but could also be considered very large because of the absence of those facilitative inputs. It is also possible that this cholinergic mechanism is necessary but not sufficient for the integration process, suggesting the possibility of other, additional synaptic mechanisms besides this one.

\section{Role of ACh in the generation of eye position signals}

Considering that persistent activity is independent of passive and/or active membrane properties of integrator neurons (Aksay et al., 2001), alternative mechanisms are required to explain the integration process. Recently, it has been demonstrated in goldfish that feedback activity among eye position-related neurons (excitatory ipsilateral and inhibitory contralateral) is necessary for temporal integration (Aksay et al., 2003). Because there is no anatomical evidence of connections between ipsilateral neurons that could explain the positive feedback (Aksay et al., 2000), a mechanism located at synaptic levels has been suggested that could operate for the short-term potentiation of synaptic inputs 

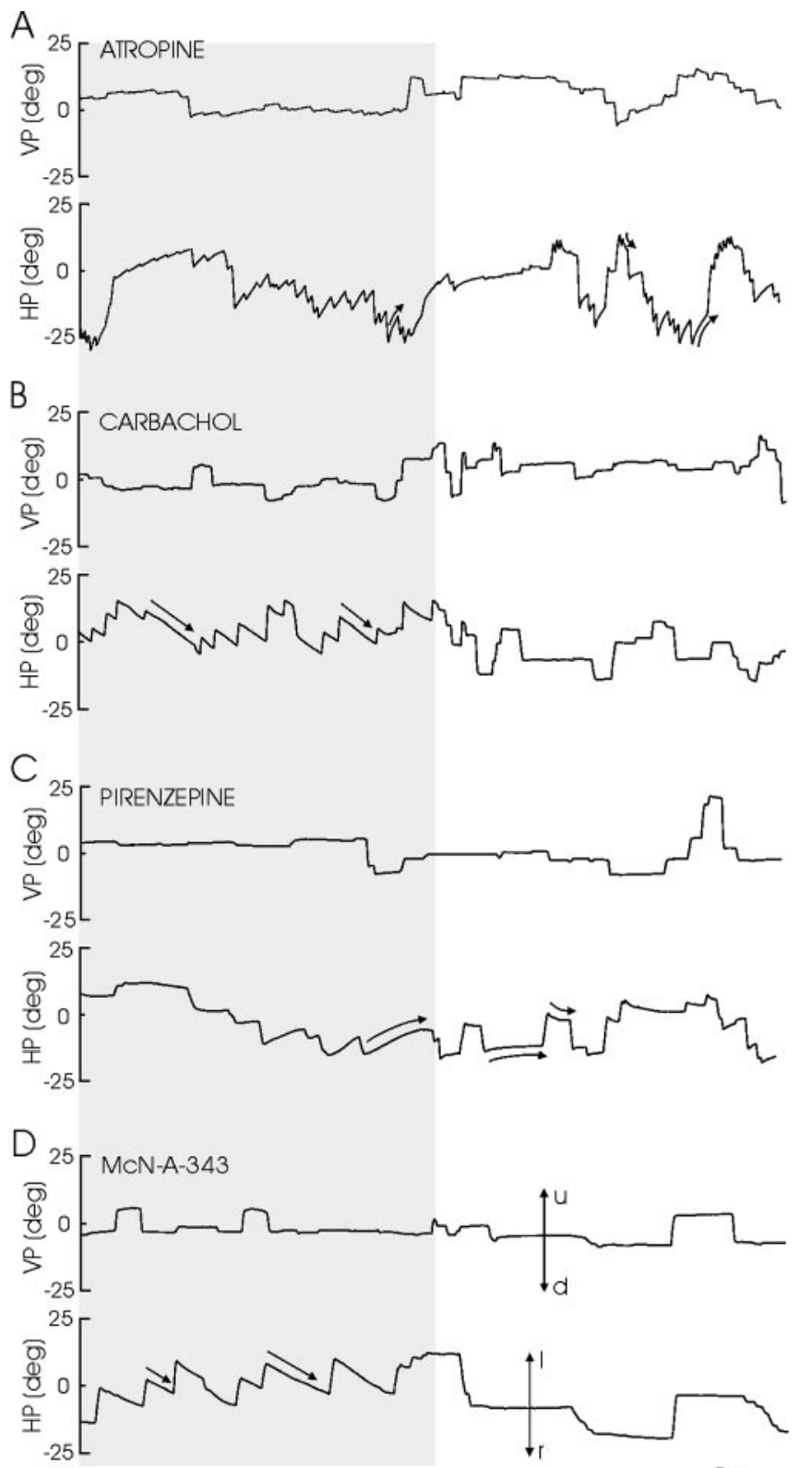

$5 \mathrm{~s}$

Figure 8. Recordings of left eye position in the vertical (VP) and horizontal (HP) planes obtained in the alert cat in complete darkness (gray lane) and in light, after the injection in the left PH of the indicated drugs. Doses and times after injection were: carbachol $(B): 1.5 \mathrm{pmol}$, $12.8 \mathrm{~min}$; McN-A-343 (D): 20 pmol, $4.5 \mathrm{~min}$; atropine $(A): 8 \mathrm{mmol}, 20.3 \mathrm{~min}$; pirenzepine $(C)$ : $0.12 \mathrm{pmol}, 4.9 \mathrm{~min}$. Eye position is plotted as degrees of rotation in the horizontal plane, positive to the left $(\mathrm{I})$ and up $(\mathrm{u})$ and negative to the right $(\mathrm{r})$ and down $(\mathrm{d})$. The zero $(0)$ indicates the central position of the eye in the orbit. The curved and straight arrows indicate the characteristics of eye movement induced by the drugs.

(eye velocity signal) triggering and maintaining depolarization in the eye position-related neurons of the integrator (Shen, 1989; Aksay et al., 2001, 2003). Our data, indicating that ACh acting on M1 muscarinic receptors is able to produce a sustained depolarization of $\mathrm{PH}$ neurons, which could certainly contribute to the neuronal integration process, are consistent with this hypothesis.

The sustained depolarization evoked by carbachol presented a slow course without significant variations of input resistance, which may be explained by induction of calcium-activated nonspecific cationic currents (Klink and Alonso, 1997; HajDahmane and Andrade, 1999; Yajeya et al., 1999). Duration and amplitude of this depolarization depend on membrane potential due to cholinergic effects on voltage-dependent $\mathrm{K}^{+}$currents (i.e., an $\mathrm{M}$ current) (Seeger and Alzheimer, 2001) or to a $\mathrm{K}^{+}$inward rectification current (Washburn and Moises, 1992). A decrease in the amplitude of the action potentials, similar to that observed in the entorhinal and prefrontal cortices, was also observed (Cantrell et al., 1996; Klink and Alonso, 1997) and was attributed to a decrease in $\mathrm{Na}^{+}$conductance, resulting from the increased availability of intracellular $\mathrm{Ca}^{2+}$ (Bulatko and Greeff, 1995; Klink and Alonso, 1997). Finally, carbachol induced a decrease in the firing rate that could be attributable to an enlargement in the mAHP as a consequence of increased intracellular $\mathrm{Ca}^{2+}$. Similar effects of charbachol-induced changes in the firing pattern have been described in the enthorinal cortex (Klink and Alonso, 1997; Egorov et al., 2002) and subiculum (Kawasaki et al., 1999). This modulation is important, considering that velocity (phasic) signals coming from the PPRF converge on PH neurons to be transformed into a position (tonic) signal that will be sent to the abducens nucleus to fix the eye after a horizontal saccade. Thus, ACh might play an important role in the integration process, modulating the firing pattern of $\mathrm{PH}$ neurons and facilitating the transformation of eye velocity signals into eye position signals. Moreover, ACh seems to have a depressant presynaptic effect on axon terminals of PPRF excitatory burst neurons. Consequently, ACh plays a complex role in the generation of persistent neuronal activity, contributing to the postsynaptic depolarization of $\mathrm{PH}$ neurons and to the presynaptic impairment of transmitter release, disfacilitating any immediate effect of excitatory burst neurons on $\mathrm{PH}$ cells after the train of impulses (i.e., after a saccade).

\section{Pharmacological studies in vivo}

In light, the pharmacological blockade of muscarinic receptors by atropine, and specifically of the M1 receptor by pirenzepine, induced an inability to maintain the eye position reached after saccades. In contrast, the less specific carbachol and the M1specific McN-A-343 agonists did not affect the generation of eye position signals because no postsaccadic drifts were observed. In darkness, ACh agonists induced a nystagmus, the slow phases of which were linear $(r>0.995)$ and directed contralaterally to the injected side, whereas antagonists induced a nystagmus with ipsilateral curved slow phases. These results were exclusive to horizontal eye movements, indicating that there was no diffusion of the applied drugs to the neighboring vestibular nuclei. The pharmacological effects of ACh agonists were in agreement with the effects induced by blockade of the GABA and glycine receptors, using the same animal preparation (Moreno-López et al., 2002), and are in accordance with the depolarization of the $\mathrm{PH}$ neurons induced by muscarinic activation in vitro. The linearity of the slow phases of the nystagmus in darkness and the correct maintenance of the eye position in light are both indicative of a correct gaze-holding system. In contrast, results obtained with ACh antagonists (i.e., curved slow phases in darkness and postsaccadic centripetal drifts in light) were indicative of a loss of eye position in the horizontal plane. These findings, similar to those obtained by the blockade of glutamatergic receptors in the $\mathrm{PH}$ nucleus of alert cats (Moreno-López et al., 2002), suggest that activation of $\mathrm{M} 1$ receptors by ACh is necessary to generate correct eye position signals after an eye saccade in the activating direction. The absence of nystagmus in light suggests that the visual input is sufficient to override any effect induced by a higher concentration of ACh agonists. 

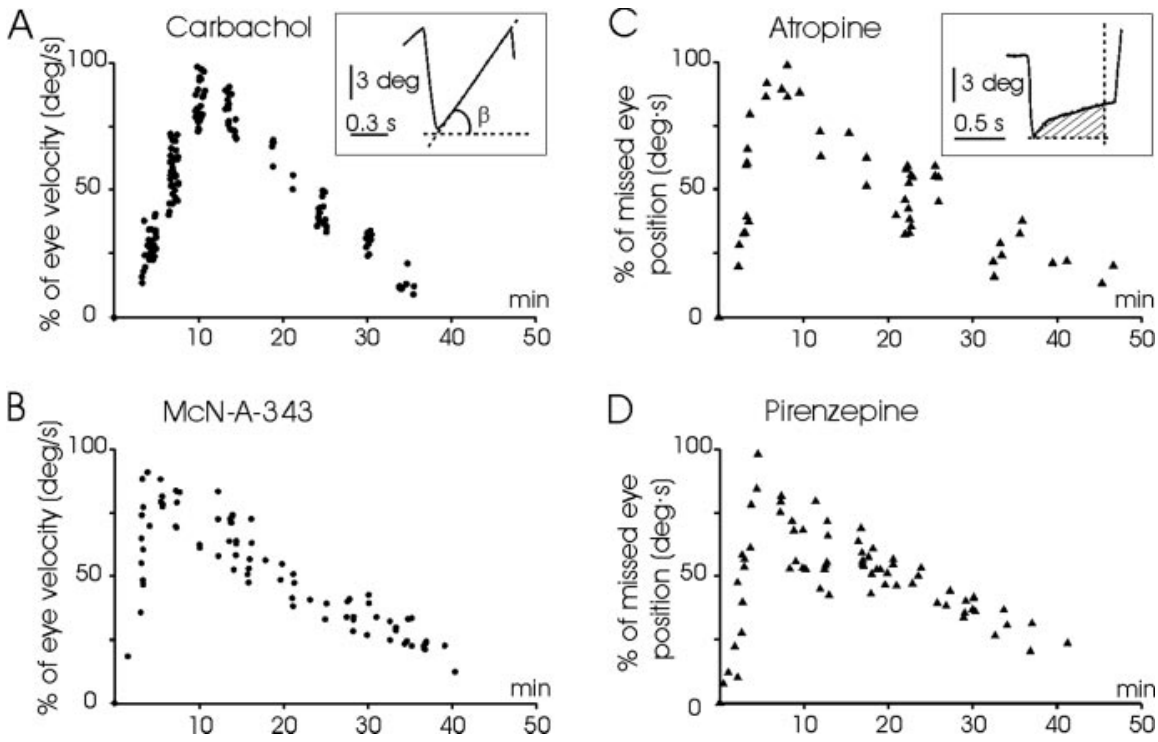

Figure 9. Time course of the effects on horizontal eye movements of ipsilateral injections in the PH nucleus of nonspecific and specific M1 receptor agonists and antagonists. Data plotted in the panels were collected from a representative injection of each drug. Each point represents (as a percentage of the maximum value) the velocity of the slow phase of the nystagmus $(A$, inset) for carbachol $(A, \bigcirc)$ and $M c N-A-343(B, O)$ in complete darkness, or the area $(C$, inset) of missed eye position during the first $0.6 \mathrm{sec}$ after a saccade for atropine $(C, \mathbf{\Delta})$ and pirenzepine $(D, \mathbf{\Delta})$ in light. Calibrations are as indicated.

Table 1. Time course of the nystagmus evoked by ipsilateral drug injections into the $\mathrm{PH}$ nucleus

\begin{tabular}{lll}
\hline Drug & $T_{\mathrm{m}}(\mathrm{min})$ & $\mathrm{T}_{50}(\min )$ \\
\hline Carbachol & $9.9 \pm 0.3$ & $18.6 \pm 1.0$ \\
McN-A-343 & $2.6 \pm 0.4$ & $15.3 \pm 4.0$ \\
Atropine & $7.4 \pm 0.2$ & $22.5 \pm 3.6$ \\
Pirenzepine & $3.8 \pm 0.4$ & $22.8 \pm 3.6$ \\
\hline
\end{tabular}

$T_{m,}$ Time necessary to reach the maximum effect: $T_{50}$, time elapsed between the injection and the moment at which $50 \%$ of the maximum effect was obtained in the response decay curve. Data are shown as means \pm SEM. Data were collected from four or more effective injections of each drug.

\section{Integrative properties of $\mathrm{PH}$ neurons}

According to the present data, the persistent activity observed in PH neurons (Escudero and Delgado-García, 1988; DelgadoGarcía et al., 1989; Escudero et al., 1992; McFarland and Fuchs, 1992) is the result, at least in part, of synaptic effects evoked by excitatory neurons in the PPRF and cholinergic neurons located probably in the pontomesencephalic region. These findings, together with the recent proposals regarding the feedback mechanism for temporal integration (Aksay et al., 2003), indicate that eye position signals arriving at the abducens nucleus could be originated in the $\mathrm{PH}$ nucleus by the effect of cholinergic inputs, subsequent to the depolarizing effects of glutamatergic PPRF inputs, and maintained by the participation of ipsilateral and contralateral reverberant circuits in the integrator (Aksay et al., 2003). Moreover, PH cholinergic neurons (Tighilet and Lacour, 1998) could be activated by collateral axons from integrator neurons, or they could represent an integral part of the involved circuits. The interplay of glutamatergic and cholinergic synaptic actions on the $\mathrm{PH}$ neurons described here is not unique because it has been reported recently that $\mathrm{PH}$ neurons are also involved in eye stability during head movements via the mediating action of nitric oxide release by some $\mathrm{PH}$ neurons on GABAergic afferents from the ipsilateral medial vestibular nucleus (Moreno-López et al., 1996, 2002). Thus, the PH nucleus could include more than one control mechanism to transform transient velocity signals into the persistent activity underlying eye positions of fixation.
Opin Neurobiol 7:872-879.

\section{References}

Aksay E, Baker R, Seung HS, Tank DW (2000) Anatomy and discharge properties of premotor neurons in the goldfish medulla that have eye-position signals during fixations. J Neurophysiol 84:1035-1049.

Aksay E, Gamkrelidze G, Seung HS, Baker R, Tank DW (2001) In vivo intracellular recording and perturbation of persistent activity in a neuronal integrator. Nat Neurosci 4:184-193.

Aksay E, Baker R, Seung HS, Tank DW (2003) Correlated discharge among cell pairs within the oculomotor horizontal velocity-to-position integrator. J Neurosci 23:10852-10858.

Arnold DB, Robinson DA, Leigh RJ (1999) Nystagmus induced by pharmacological inactivation of the brainstem ocular motor integrator in monkey. Vision Res 39:4286-4295.

Barmack NH, Baughman RW, Eckenstein FP Shojaku H (1992) Secondary vestibular cholinergic projection to the cerebellum of rabbit and rat as revealed by choline acetyltransferase immunohistochemistry, retrograde and orthograde tracers. J Comp Neurol 317:250-270.

Bulatko AK, Greeff NG (1995) Functional availability of sodium channels modulated by cytosolic free $\mathrm{Ca}^{2+}$ in cultured mammalian neurons (N1E-115). J Physiol (Lond) 484:307-312.

Büttner-Ennever JA, Horn AKE (1997) Anatomical substrates of oculomotor control. Curr

Cannon SC, Robinson DA (1987) Loss of the neuronal integrator of the oculomotor system from brain stem lesions in monkey. J Neurophysiol 57:1383-1409.

Cannon SC, Robinson DA, Shamma S (1983) A proposed neural network for the integrator of the oculomotor system. Biol Cybern 49:127-136.

Cantrell AR, Ma JY, Scheuer Y, Catterall WA (1996) Muscarinic modulation of sodium current by activation of protein kinase $\mathrm{C}$ in rat hippocampal neurons. Neuron 16:1019-1026.

Carpenter MB, Chang L, Pereira AB, Hersh LB (1987) Comparisons of the immunocytochemical localization of choline acetyltransferase in the vestibular nuclei of the monkey and rat. Brain Res 418:403-408.

Cheron G, Godaux E (1987) Disabling of the oculomotor neuronal integrator by kainic acid injections in the prepositus-vestibular complex in the cat. J Physiol (Lond) 399:267-290.

Cheron G, Godaux E, Laune JM, Vanderkelen B (1986) Lesion in the cat prepositus complex: effects on the vestibulo-ocular reflex and saccades. J Physiol (Lond) 372:75-94.

Delgado-García JM (2000) Why move the eyes if we can move the head? Brain Res Bull 52:475-482.

Delgado-García JM, Vidal P-P, Gómez C, Berthoz A (1989) A neurophysiological study of prepositus hypoglossi neurons projecting to oculomotor and preoculomotor nuclei in the alert cat. Neuroscience 29:291-307.

Egorov EV, Hamam BN, Fransén E, Hasselmo ME, Alonso A (2002) Graded persistent activity in entorhinal cortex neurons. Nature 420:173-178.

Escudero M, Delgado-García JM (1988) Behav of reticular, vestibular and prepositus neurons terminating in the abducens nucleus of the alert cat. Exp Brain Res 71:218-222.

Escudero M, de la Cruz RR, Delgado-García JM (1992) A physiological study of vestibular and prepositus hypoglossi neurones projecting to the abducens nucleus in the alert cat. J Physiol (Lond) 458:539-560.

Faber ESL, Sah P (2002) Physiological role of calcium-activated potassium currents in the rat lateral amygdala. J Neurosci 22:1618-1628.

Fernández de Sevilla D, Cabezas C, Oshima de Prada AN, Sánchez-Jiménez A, Buño W (2002) Selective muscarinic regulation of functional glutamatergic Schaffer collateral synapses in rat CA1 pyramidal neurons. J Physiol (Lond) 545:51-63.

Fukushima K, Kaneko CRS, Fuchs AF (1992) The neuronal substrate of integration in the oculomotor system. Prog Neurobiol 39:609-639.

Goldman MS, Levine JH, Major G, Tank DW, Seung HS (2003) Robust persistent neuronal activity in a model integrator with multiple hysteretic dendrites per neuron. Cereb Cortex 13:1185-1195. 
Haj-Dahmane S, Andrade R (1999) Muscarinic receptors regulate two different calcium-dependent non-selective cation currents in rat prefrontal cortex. Eur J Neurosci 11:1973-1980.

Higo S, Ito K, Fuchs D, McCarley RM (1990) Anatomical interconnections of the pedunculopontine tegmental nucleus and the nucleus prepositus hypoglossi in the cat. Brain Res 536:79-85.

Huang CC, Hsu KS, Gean PW (1996) Isoproterenol potentiates synaptic transmission primarily by enhancing presynaptic calcium influx via $\mathrm{P}$ and/or Q-type calcium channels in the rat amygdala. J Neurosci 16:1026-1033.

Igusa A, Sasaki S, Shimazu H (1980) Excitatory premotor burst neurons in the cat pontine reticular formation related to the quick phase of vestibular nystagmus. Brain Res 182:451-456.

Kawasaki H, Pamieri C, Avoli M (1999) Muscarinic receptor activation induces depolarizing plateau potentials in subicular bursting cells. J Neurophysiol 82:2590-2601.

Keller EL, Kamath BY (1975) Characteristics of head rotation and eye movement-related neurons in alert monkey vestibular nucleus. Brain Res 100:182-187.

Klink R, Alonso A (1997) Ionic mechanism of muscarinic depolarization in entorhinal cortex layer II neurons. J Neurophysiol 77:1829-1843.

López-Barneo J, Darlot C, Berthoz A, Baker R (1982) Neuronal activity in prepositus nucleus correlated with eye movement in the alert cat. J Neurophysiol 47:329-352.

Marchi M, Risso F, Viola C, Cavazzani P, Raiteri M (2002) Direct evidence that release-stimulating $\alpha 7$ nicotinic cholinergic receptors are localized on human and rat brain glutamatergic axon terminals. J Neurochem 80:1071-1078.

McCrea R, Baker R (1985a) Cytology and intrinsic organization of the perihypoglossal nuclei in the cat. J Comp Neurol 237:360-376.

McCrea R, Baker R (1985b) Anatomical connections of the nucleus prepositus of the cat. J Comp Neurol 237:377-407.

McDonald AJ (1992) Neuroanatomical labeling with biocytin: a review. NeuroReport 3:821-827.

McFarland JL, Fuchs AF (1992) Discharge patterns in nucleus prepositus hypoglossi and adjacent medial vestibular nucleus during horizontal eye movement in behaving macaques. J Neurophysiol 68:319-332.

Mennerick S, Zorumsky CF (1995) Paired-pulse modulation of fast excitatory synaptic currents in microcultures of rat hippocampal neurons. J Physiol (Lond) 488:85-101.

Moises HC, Womble MD, Washburn MS, Williams LR (1995) Nerve growth factor facilitates cholinergic neurotransmission between nucleus basalis and the amygdala in the rat: an electrophysiological analysis. J Neurosci 15:8131-8142.
Moreno-López B, Escudero M Delgado-García JM, Estrada C (1996) Nitric oxide production by brain stem neurons is required for normal performance of eye movements in alert animals. Neuron 17:739-745.

Moreno-López B, Escudero M, Estrada C (2002) Nitric oxide facilitates GABAergic neurotransmission in the cat oculomotor system: a physiological mechanism in eye movement control. J Physiol (Lond) 540:295-306.

Moschovakis AK (1997) The neuronal integrators of the mammalian saccadic system. Front Biosci 15:D552-D577.

Moschovakis AK, Scudder CA, Highstein SM (1996) The microscopic anatomy and physiology of the mammalian saccadic system. Prog Neurobiol 50:133-254.

Navarro JD, Alvarado JC, Escudero M, Delgado-García JM, Yajeya J (2003) A cholinergic mechanism underlies persistent neuronal activity necessary for eye fixation. Soc Neurosci Abstr 391.20.

Pastor A, de la Cruz RR, Baker R (1994) Eye position and eye velocity integrators reside in separate brainstem nuclei. Proc Natl Acad Sci USA 91:807-811.

Robinson DA (1981) The use of control system analysis in the neurophysiology of eye movements. Annu Rev Neurosci 4:463-503.

Seeger T, Alzheimer C (2001) Muscarinic activation of inwardly rectifying $\mathrm{K}(+)$ conductance reduces EPSPs in rat hippocampal CA1 pyramidal cells. J Physiol (Lond) 535:383-396.

Semba K, Reiner PB, Fibiger HC (1990) Single cholinergic mesopontine tegmental neurons project to both the pontine reticular formation and the thalamus in the rat. Neuroscience 38:643-654.

Shen L (1989) Neural integration by short term potentiation. Biol Cybern 61:319-325.

Thompson AL (2000) Facilitation, augmentation and potentiation at central synapses. Trends Neurosci 23:305-312.

Tighilet B, Lacour M (1998) Distribution of choline acetyltransferase immunoreactivity in the vestibular nuclei of normal and unilateral vestibular neurectomized cats. Eur J Neurosci 10:3115-3126.

Washburn MS, Moises HC (1992) Muscarinic responses of rat basolateral amygdaloid neurons recorded in vitro. J Physiol (Lond) 449:121-154.

Yajeya J, de la Fuente Juan A, Bajo VM, Riolobos AS, Heredia M, Criado JM (1999) Muscarinic activation of a non-selective cationic conductance in pyramidal neurons in rat basolateral amygdala. Neuroscience $88: 159-167$

Yajeya J, de la Fuente A, Criado JM, Bajo V, Sánchez-Villalobos A, Heredia M (2000) Muscarinic agonistic carbachol depresses excitatory synaptic transmission in the rat basolateral amygdala in vitro. Synapse 38:151-160. 